\title{
La psicomotricitat en \\ l'àmbit escolar: un \\ estudi de cas
}

\section{Isabel Viscarro Tomàs ${ }^{a}$, Saturnino Gimeno Martín ${ }^{b}$ i Montserrat Anton Rosera $^{c}$}

Rebut: 16/05/2011 Acceptat: 06/06/2011

\section{Resum}

En aquest article es descriu l'estat de la psicomotricitat a les escoles d'educació infantil de la província de Tarragona. Donada l'amplitud de la investigació, aquí, tan sols se'n presenta una part. Concretament, la que té com a objectiu aportar informació sobre la tipologia del centre i la seva situació geogràfica, així com la valoració que des del centre es fa de la psicomotricitat. També contempla els aspectes organitzatius d'aquesta pràctica. L'estudi es realitza en un període de set cursos acadèmics.

En la investigació hi han participat 109 escoles distribuïdes en 55 municipis a l'inici de l'estudi i 116 escoles repartides en 65 localitats al final del període estudiat, amb representació a les 10 comarques tarragonines.

Finalment, es mostren els resultats fent una anàlisi comparativa dels diferents ítems entre el curs d'inici i el del final de l'estudi i es presenten les conclusions d'acord amb els objectius plantejats.

Paraules clau: Psicomotricitat. Escoles d'educació infantil. Comarques de Tarragona

\section{Abstract}

This article describes the state of psychomotive practice in nursery education schools of the region of Tarragona. Due to the width of the research only one part is shown. The aim of this section is to provide with information about the type of centre and its location, as well as the evaluation of psycho motive practice from the centre. The organizational aspects of this practice are also included. The research has been carried out over a period of seven academic years.

\footnotetext{
a Departament de Pedagogia - Universitat Rovira i Virgili

${ }^{b}$ Departament de Pedagogia - Universitat Rovira i Virgili

' Departament de Didàctica de I'Expressió musical, Plàstica i Corporal. Universitat Autònoma de Barcelona
} 
109 schools from 55 towns took part at the beginning of the research and other 116 from 65 towns participated at the end of the study, thus including the 10 regions of Tarragona.

Finally, the results are shown comparing the different items between the beginning and the end of the study as well as the conclusions according to the considered objectives.

Key words: Psychomotive practice. Nursery education. Regions of Tarragona

\section{Introducció}

La majoria d'autors coincideixen en què la infància és un període d'importància cabdal en la construcció de la persona. És en l'etapa de zero a sis anys que es produeixen els canvis més significatius en el desenvolupament global de l'ésser humà. A través de la relació amb els altres els infants es construeixen en aquesta etapa una primera representació del món i de si mateixos.

La bibliografia referida a l'estudi del moviment humà és extensa i variada. La seva consulta evidencia l'existència de diferents teories i línies de treball relatives a l'estudi del moviment i el seu desenvolupament. Centrarem l'atenció en aquelles que es proposen comprendre el paper que té el moviment en la construcció del coneixement $\mathrm{i}$ en el desenvolupament de la personalitat. Són nombrosos els autors que des de l'àmbit de la investigació i de la pràctica educativa argumenten que el moviment està en la base dels processos de desenvolupament infantil i de construcció de la personalitat.

Les obres de $\mathrm{H}$. Wallon $(1934,1942,1947)$ mostren la importància del moviment en el desenvolupament psicològic de l'infant. En els primers anys de vida, les experiències viscudes amb el cos i a través del cos i del moviment i les seves interaccions són fonamentals per a la construcció de la personalitat infantil i per a l'adquisició de la pròpia identitat. L'autor argumenta que el moviment és una font inesgotable d'experiències, és origen del coneixement i dels afectes que, quan s'exterioritzen, es converteixen en el primer llenguatge d'expressió de la persona (Wallon, 1969). Deslligar el moviment del coneixement i dels aspectes emocionals resulta difícil, tot i que durant molts anys s'ha considerat la persona més com un ésser que pensa i que sent que no pas com un ésser que actua, cosa que deixava l'activitat motriu en un segon terme.

La importància de la motricitat, l'acció, el joc i l'experimentació com a elements bàsics de l'aprenentatge és avalada per una àmplia investigació pedagògica i psicològica que ha contribuït a fonamentar els principis educatius de l'etapa d'Educació Infantil des d'una perspectiva integral. Des d'autors clàssics com J.J. Rosseau (1762), H. Wallon (1934, 1942, 1947), J. Piaget (1961, 1975), A. Gessell (1945), L.S. Vigostky (1979), J. Ajuriaguerra (1979), M. Montessori (1937), entre d'altres, fins a especialistes més actuals com J. Delval (2003), A. Perinat ((2003), J. le Boulch $(1972,1982,1983)$, A. 
Lapierre i B. Aucouturier (1977), B.J. Cratty (1982), J.L. Pastor (1994, 2002), M. Antón (1979, 1986), P.P. Berruezo (1995), N. Franc (2001), M. Vaca (1986, 1996), per citar-ne alguns.

El fet d'haver centrat la investigació en la pràctica de la psicomotricitat en l'Educació Infantil es justifica per raons acadèmiques, professionals i socials.

A més a més de les aportacions d'aquests autors, hi ha altres raons que ens ha conduit a realitzar aquest estudi, aquestes venen de lluny i són diverses. La tasca professional a l'escola impartint l'educació física en els diferents etapes educatives ha permès veure la importància del moviment en el desenvolupament dels infants. La docència amb l'alumnat de Preescolar o d'Educació Infantil com s'anomenà posteriorment, van fer créixer l'interès per la Psicomotricitat, la necessitat d'aprofundir més en el seu estudi i la motivació per fer una formació específica en aquest àmbit. Aquest fet va desencadenar que a l'any 90 entrés més de ple en aquest món. Per una banda, creant un projecte d'educació psicomotriu junt amb el professor Joan Fuguet aleshores director del collegi de Pràctiques, projecte i col-laboració que encara segueix vigent i que posteriorment també ha beneficiat a altres professionals de la facultat que l'han incorporat en les seves pràctiques docents tant de grau com de postgrau. Per altra banda, impartint cursos de formació permanent de psicomotricitat als i les mestres. Les dues experiències ens han permès fer una recerca-acció en psicomotricitat que ha repercutit en el plantejament metodològic de les escoles i en la formació tant inicial com permanent dels mestres, amb el convenciment que l'educació psicomotriu ha de ser una pràctica de qualitat que contribueixi al desenvolupament integral de l'infant.

En aquests darrers anys s'estan produint un seguit d'esdeveniments que mostren l'impuls que està adquirint la psicomotricitat. Prova d'això és la realització de congressos i jornades d'àmbit internacional, nacional i autonòmic. També ho ratifiquen la creació i la consolidació de grups de treball i de recerca, formats per professionals vinculats a la temàtica, per tal d'investigar, reflexionar, aprofundir i elaborar materials tant d'estudi com didàctics a partir de les pròpies experiències. Això implica un augment considerable en les produccions relacionades directament o indirectament amb la psicomotricitat: publicacions de llibres, d'articles en revistes especialitzades i de material audiovisual.

Situats en el terreny de la pràctica educativa, s'ha fet necessari, en moments de canvis socials ràpids $i$ estructurals com els que s'estan vivint, aprofundir en un tipus de plantejament educatiu orientat cap a l'infant. Aquesta cerca ha estat dirigida cap a metodologies capaces de donar resposta a les seves necessitats tot respectant la globalitat des de la qual actuen, s'expressen i es relacionen, per superar així les contradiccions, que poden donar-se entre teoria i pràctica educativa.

La psicomotricitat, entesa com una manera de fer, d'estar i, per tant, de facilitar el procés de desenvolupament i d'aprenentatge dels infants de cero a sis anys, se situa al centre de la pràctica educativa i impregna tota l'activitat escolar. La sessió de psicomotricitat realitzada de manera sistemàtica, continuada i estable facilita un espai 
i un temps específics per a la vivència del plaer psicomotor. És un context educatiu privilegiat, és un camp d'assaig i d'experimentació que, en un marc de relació amb els altres, incideix de manera significativa en el desenvolupament integral de l'infant. Per això, s'ha plantejat l'estudi que es presenta, per conèixer la realitat de l'escola, amb el convenciment que la psicomotricitat és fonamental en aquestes edats, és el motor del desenvolupament integral i dels aprenentatges.

\section{Contextualització de la investigació}

L'estudi s'ha realitzat en un període de set anys. Els motius que han portat a delimitar-lo són dos.

D'una banda, la formació permanent dels professionals, ja que la recerca es va iniciar el curs 1998-99, abans de l'oferta formativa de postgrau a la Universitat Rovira i Virgili, i va finalitzant set cursos després, el curs 2005-06, coincidint amb l'ultima edició de curs de postgrau d'aquesta dècada organitzada des del Departament de Pedagogia de la URV. El període de set cursos acadèmics es va considerar temps suficient per a l'estudi que es volia realitzar.

D'altra banda, legislativament, per centrar l'estudi en la mateixa Llei d'educació, en un moment de plena aplicació de la LOGSE en el seu tram final.

\section{Objectius}

Els objectius que han guiat l'estudi son:

- Conèixer la valoració de la psicomotricitat per part dels centres educatius.

- Comparar l'evolució de la psicomotricitat al llarg del període estudiat.

- Saber qui realitza la sessió de psicomotricitat a les escoles.

- Tenir coneixement de si els centres educatius disposen de projecte de psicomotricitat.

\section{Metodologia}

La perspectiva metodològica que s'ha seguit per realitzar aquest estudi ha estat "mixta", s'ha combinat la metodologia quantitativa i la qualitativa.

Al tractar-se d'una investigació orientada al coneixement de la pràctica educativa, també s'ha tingut en compte la recerca-acció en la modalitat participativa (V. Ferreres i A.P. González, 2006), en la que un grup d'experts de l'àmbit d'aquesta pràctica a les escoles han participat en la revisió dels resultats, un cop fet l'anàlisi i la valoració dels mateixos, tenint en compte les seves aportacions. 
Per donar resposta als objectius de la investigació s'ha optat pel qüestionari com a mètode de recollida de informació. La tria d'aquest instrument metodològic permet obtenir informació tan qualitativa com quantitativa. Per al disseny del qüestionari, procés complex i delicat, s'han seguit les orientacions de Sierra Bravo (1994), Duverger (1996) i Tejada (1997). Una vegada dissenyat el qüestionari es va procedir a la seva validació que va ser realitzada per un grup d'experts format per especialistes en psicomotricitat i per professionals de l'àmbit educatiu.

El qüestionari estava constituït per 66 ítems. El seu contingut es va estructurar en quatre grans dimensions, d'acord amb les principals variables que hi intervenen:

a) Anàlisi del centre educatiu, 12 ítems.

b) Dades personals, professionals i formació en psicomotricitat dels docents que porten a terme la pràctica, 15 ítems.

c) Enfocament pedagògic de la psicomotricitat, 34 ítems.

d) La psicomotricitat al currículum, 5 ítems.

Aquest article, donada l'amplitud dels resultats, se centra en els ítems de la primera dimensió del qüestionari, els corresponents a l'anàlisi del centre educatiu que es descriuen seguidament:

- Distribució dels centres participants per comarques i per nombre de municipis.

- $\quad$ Tipus de població.

- Tipus de centre.

- Valoració de la psicomotricitat per part de l'escola.

- $\quad$ Edat a qui va adreçada la pràctica psicomotriu.

- $\quad$ Àmbit en el què es realitza el treball psicomotriu.

- Existència de projecte de psicomotricitat al centre.

- $\quad$ Any de realització del projecte.

- Responsable de definir el projecte.

- Nombre de docents que realitzen psicomotricitat al centre.

- Grau de coordinació entre els docents que realitzen psicomotricitat

- Tres termes significatius en relació all concepte de psicomotricitat.

Tots els ítems, excepte un, són de resposta tancada i la valoració es fa en una escala de I'1 al 6. L'últim ítem és de resposta oberta, en aquest cas, s'han establert categories per similituds semàntiques. 


\section{Mostra}

La distribució dels qüestionaris es va fer de forma equitativa per les deu comarques tarragonines, tot i així, els percentatges que formen la mostra van ser heterogenis en les diferents comarques.

La taula número 1, mostra la relació de centres d'Educació Infantil i Primària (CEIP) i d'escoles d'Educació Infantil (EEI) distribuïdes per comarques els dos cursos en que es va aplicar el qüestionari. També es pot observar la representativitat de la població participant en freqüències i percentatges.

\begin{tabular}{|c|c|c|c|c|c|c|}
\hline \multirow{3}{*}{$\begin{array}{l}\text { Comarca } \\
\text { Alt Camp }\end{array}$} & \multirow{2}{*}{\multicolumn{2}{|c|}{$\begin{array}{c}\text { Total centres: } \\
\text { CEIP i EEI }{ }^{1}\end{array}$}} & \multicolumn{4}{|c|}{ Centres participants } \\
\hline & & & \multicolumn{2}{|c|}{ Freqüència } & \multicolumn{2}{|c|}{ Percentatge } \\
\hline & 34 & 36 & 10 & 8 & $29,41 \%$ & $22,22 \%$ \\
\hline Baix Camp & 75 & 82 & 20 & 19 & $26,67 \%$ & $23,17 \%$ \\
\hline Baix Ebre & 40 & 40 & 12 & 15 & $30,00 \%$ & $37,50 \%$ \\
\hline Baix Penedès & 33 & 40 & 13 & 11 & $39,39 \%$ & $27,50 \%$ \\
\hline Conca de Barberà & 16 & 18 & 3 & 7 & $18,75 \%$ & $38,89 \%$ \\
\hline Montsià & 25 & 26 & 10 & 8 & $40,00 \%$ & $30,77 \%$ \\
\hline Priorat & 17 & 17 & 4 & 5 & $23,53 \%$ & $29,41 \%$ \\
\hline Ribera d'Ebre & 20 & 22 & 2 & 5 & $10,00 \%$ & $22,73 \%$ \\
\hline Tarragonès & 82 & 93 & 31 & 35 & $37,80 \%$ & $37,63 \%$ \\
\hline Terra Alta & 14 & 13 & 4 & 3 & $28,57 \%$ & $23,08 \%$ \\
\hline Mitjana & & & & & $28,41 \%$ & $29,29 \%$ \\
\hline Total & 356 & 387 & 109 & 116 & & \\
\hline
\end{tabular}

Taula 1. Total de població i nivell de participació dels centres distribuïts per comarques

\section{Presentació $\mathbf{i}$ anàlisi dels resultats}

La descripció i l'anàlisi dels resultats es presenta seguint l'ordre dels ítems que conformen aquesta dimensió del qüestionari.

La població que ha respost al qüestionari està constituïda per 109 docents el curs 1998-99 i 116 docents el curs 2005-06. Els professionals que han participat estan treballant en centres educatius (un per centre) distribuïts en diferents localitats. La 
taula següent permet observar la resposta obtinguda en relació al nombre de municipis:

\begin{tabular}{|c|c|c|c|c|}
\hline COMARCA & \multicolumn{2}{|c|}{ CENTRES } & \multicolumn{2}{|c|}{ MUNICIPIS } \\
\hline Alt Camp & 10 & 8 & 4 & 4 \\
\hline Baix Camp & 20 & 19 & 7 & 7 \\
\hline Baix Ebre & 12 & 15 & 4 & 5 \\
\hline Baix Penedès & 13 & 11 & 7 & 10 \\
\hline Conca de Barberà & 3 & 7 & 3 & 5 \\
\hline Montsià & 10 & 8 & 7 & 7 \\
\hline Priorat & 4 & 5 & 4 & 5 \\
\hline Ribera d'Ebre & 3 & 5 & 3 & 3 \\
\hline Tarragonès & 31 & 35 & 10 & 12 \\
\hline Terra Alta & 3 & 3 & 3 & 3 \\
\hline
\end{tabular}

Taula 2. Distribució dels centres per comarques i localitats

La distribució de centres participants per comarques es presenta en el gràfic 1 :

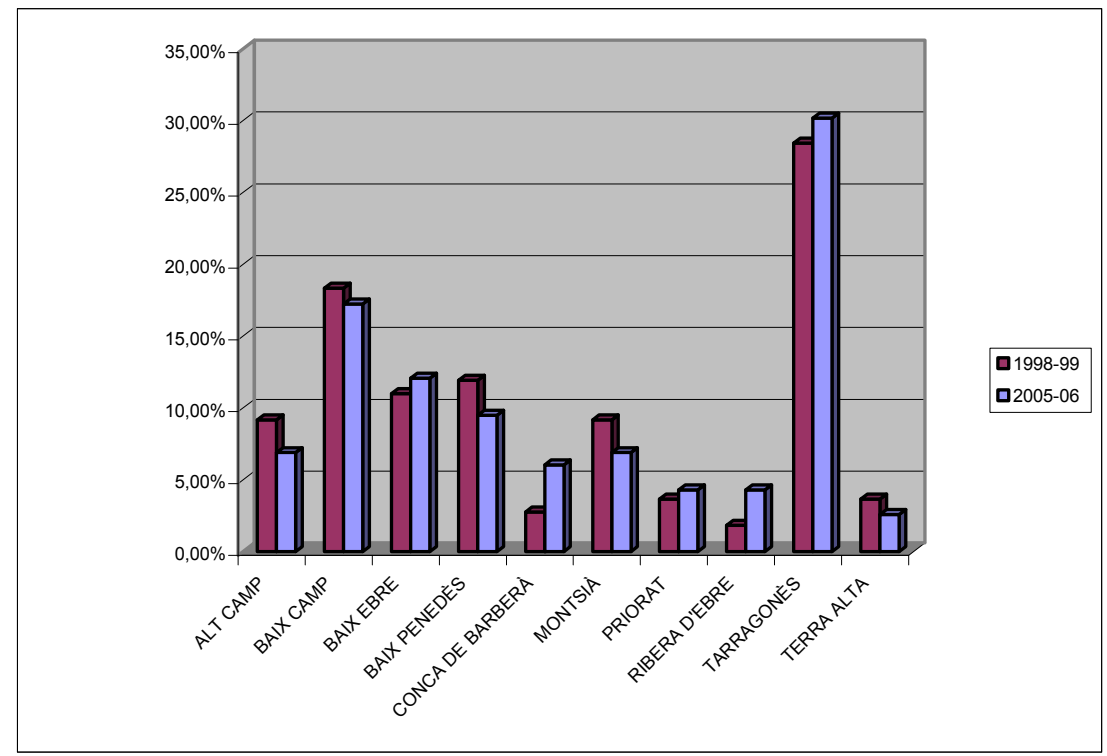

Gràfic 1. Distribució dels centres participants per comarques

Com es pot veure, de les deu comarques que formen part de l'estudi, amb relació al curs 1998-99 en la meitat ha augmentat el percentatge de centres participants i en 
l'altra meitat els percentatges de participació han estat més baixos. L'augment més significatiu ha estat a la Conca de Barberà, que ha passat del $\mathbf{2 , 7 \%}$ al $\mathbf{6 \%}$ de participació, i la comarca on el percentatge de participació ha baixat més ha estat el Baix Penedès, que ha passat de I' $11,9 \%$ al $9,4 \%$.

S'observa que a les comarques amb una concentració de població més alta el nombre de centres és molt elevat amb relació al nombre de municipis participants. Amb relació al nombre de centres, les diferències entre la primera i la segona aplicació del qüestionari no són gaire destacades.

En el gràfic número 2 es presenta el nombre de qüestionaris rebuts en funció del tipus de població ${ }^{2}$ en què es troben ubicats els centres:

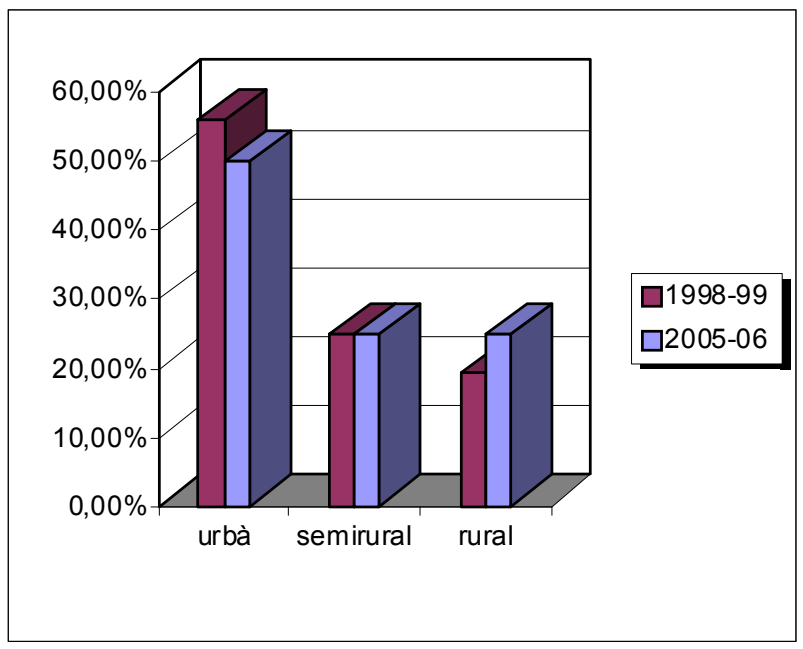

Gràfic 2. Tipus de població

S'observa un ampli predomini de centres situats en municipis urbans, el 55,9\% i el $50 \%$ respectivament, tant en la primera com en la segona aplicació del qüestionari. El percentatge de centres restants està distribuït en localitats intermèdies i rurals. El curs 1998-99 hi ha un lleuger predomini de centres situats en municipis semirurals $(24,7 \%)$ enfront dels municipis rurals (19,2\%). El curs 2005-06, la distribució entre aquests tipus de localitats és equitativa, un $25 \%$ de centres en cada tipus de població.

Els centres educatius participants responen a una de les següents tipologies: públic, concertat o privat: 


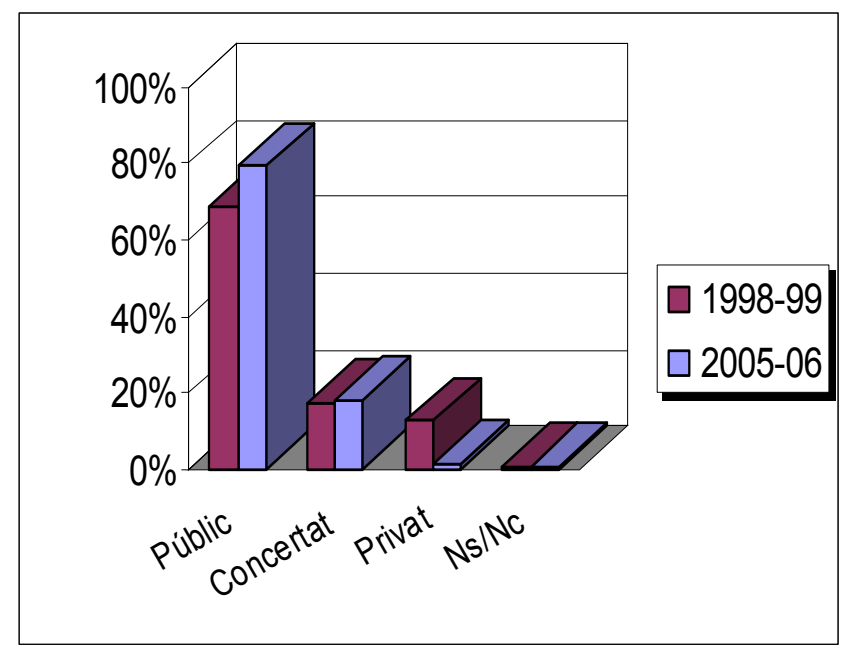

Gràfic 3. Tipus de centre

Es pot observar al gràfic número 3 que aquest estudi està centrat sobretot en centres públics. El curs 1998-99 gairebé el 69\% dels centres participants eren públics. Aquesta majoria augmenta encara més amb els resultats obtinguts el curs 2005-06, en què gairebé el $80 \%$ dels centres eren públics. En segona posició, i a molta distància, trobem els centres concertats, amb el $17,4 \%$ i el $18,1 \%$ respectivament.

Cal destacar les grans diferències entre la primera i la segona aplicació respecte als centres privats: mentre que el curs 1998-99 el 12,8\% dels centres eren privats, el curs 2005-06 tan sols van representar l'1,7\%.

Valoració: el nombre de centres de titularitat pública a la província és més elevat que el de centres concertats i privats. Aquest fet pot justificar l'alta participació dels primers. També cal destacar que una possible causa en la disminució dels centres privats amb relació a la primera aplicació de l'instrument pot ser deguda a l'augment progressiu de CEIP i, especialment, de llars d'infants municipals. Centres, per tant, de titularitat pública que s'han creat els darrers anys i que han participat en la segona aplicació de l'instrument.

La importància que es dóna a la pràctica psicomotriu per part del centre és un dels aspectes que es volien indagar: 


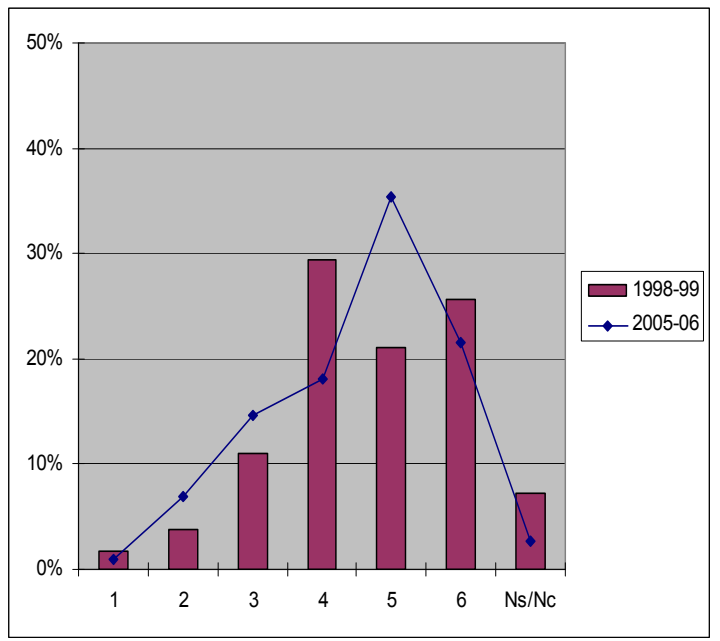

Gràfic 4. Valoració de la psicomotricitat

Com s'observa al gràfic número 4, en els resultats obtinguts en les dues aplicacions, la puntuació atorgada a la pregunta ha estat força important. Si es pren com a referència l'escala de l'1 al 6, el curs 1998-99 més del 75\% dels entrevistats van puntuar-la en la franja alta de l'escala. En concret, gairebé el 30\% va atorgar un 4 a la valoració realitzada pel centre respecte a la pràctica psicomotriu, el $21,1 \%$ la va puntuar amb un 5 i el $25,7 \%$ amb un 6 .

Pel que fa al curs 2005-06, els entrevistats van augmentar substancialment la puntuació. Encara que es manté el $75 \%$ de puntuacions superiors al 3, més del 35,5\% la van puntuar amb un 5 .

Valoració: sembla que hi ha una major conscienciació de la importància de la psicomotricitat per part dels centres, ja que un percentatge força elevat de professionals la valora amb les puntuacions altes de l'escala: important o molt important. Alguns dels enquestats destaquen que seria important que tot l'equip partís de la mateixa línia metodològica per fer sessions de psicomotricitat.

En relació a l'edat a la qual va adreçada la pràctica psicomotriu, els gràfics es presenten per separat perquè, en el segon qüestionari, s'hi va fer alguna modificació.

En el primer, del curs 1998-99, es contemplava la franja de 6 a 8 anys, edat en la qual encara es treballa la psicomotricitat. En la revisió del qüestionari per a la segona aplicació, el curs 2005-06, es va considerar més oportú centrar la recerca en l'alumnat d'Educació Infantil (0-6 anys). 


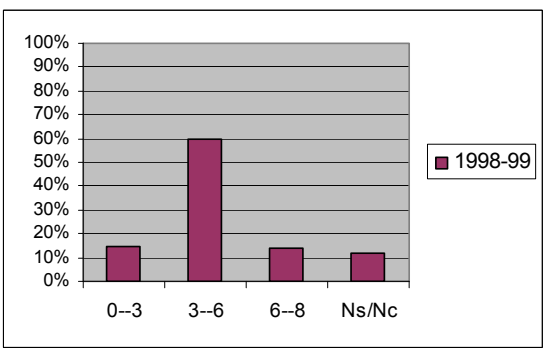

Gràfic 5. Franja d'edat curs 1998-99

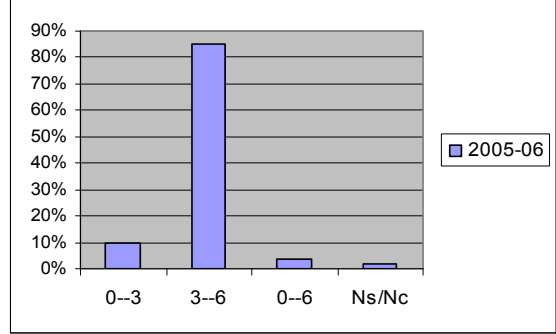

Gràfic 6. Franja d'edat curs 2005-06

La comparativa que es pot fer amb les dades de les dues aplicacions del qüestionari no és exacta, ja que hi ha una diferència en les opcions dels grups d'edat de la població, com ja s'ha comentat. Es pot observar que les respostes obtingudes apunten majoritàriament el segon cicle d'Educació Infantil, parvulari. Aquest grup d'edat, de 3 a 6 anys, el destaquen pràcticament el 60\% dels professionals participants el curs 1998-99. Pel que fa al curs 2005-06, el percentatge s'incrementa fins al $85,34 \%$.

Valoració: aquest resultat era molt previsible, la major part dels centres de la mostra atenen nens i nenes de 3 a 12 anys, és a dir, de segon cicle d'Educació Infantil i d'Educació Primària. Algun col-legi concertat té el cicle de llar d'infants i també hi han participat llars d'infants, tot i que de forma minoritària.

L'àmbit en el qual es realitza el treball psicomotriu, de la mateixa manera que en la pregunta anterior, els gràfics el presenten per separat, en no tenir els mateixos elements de comparació. En el segon qüestionari es va considerar oportú incloure com a possible resposta l'àmbit terapèutic, tot i que som conscients que aquest àmbit no s'ha de contemplar a l'escola ordinària. La seva inclusió es va considerar per la participació d'algun centre d'educació especial.

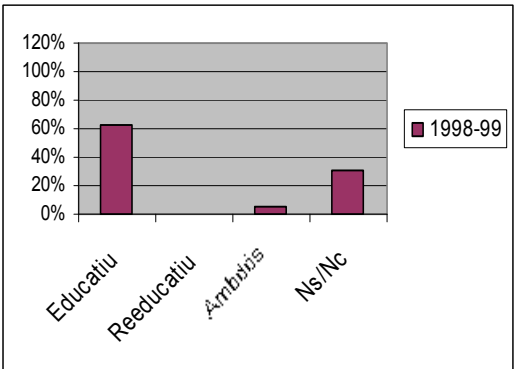

Gràfic 7. Àmbit d'intervenció curs 1998-99

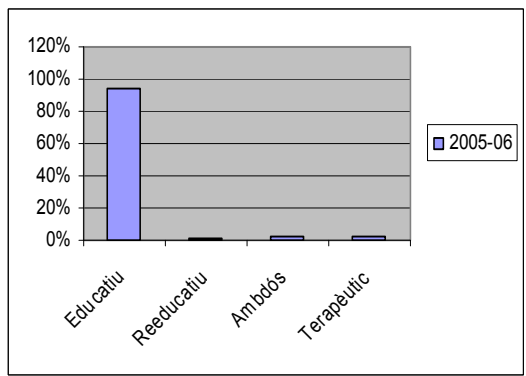

Gràfic 8. Àmbit d'intervenció curs 2005-06 
Es pot comprovar que en els dos cursos del període estudiat l'àmbit de treball més representatiu és l'educatiu. Amb el 63,3\% el curs 1998-99 i més del 95\% el curs 200506.

S'observa que el curs 2005-06 les respostes obtingudes en total són 119, 3 més que l'univers total d'entrevistats. Es tracta de 3 qüestionaris amb respostes múltiples: dos fan referència als àmbits reeducatiu i terapèutic, i responen a dos centres d'educació especial. El tercer respon de forma errònia "educatiu" i "reeducatiu" en comptes d'"ambdós".

Conèixer si existeix un projecte de psicomotricitat al centre semblava rellevant. $\mathrm{Ha}$ permès analitzar de quina manera es contempla i s'insereix la psicomotricitat en els principis educatius i els trets d'identitat de l'escola i garanteix una línia de treball de centre, de la mateixa manera que en les altres matèries.

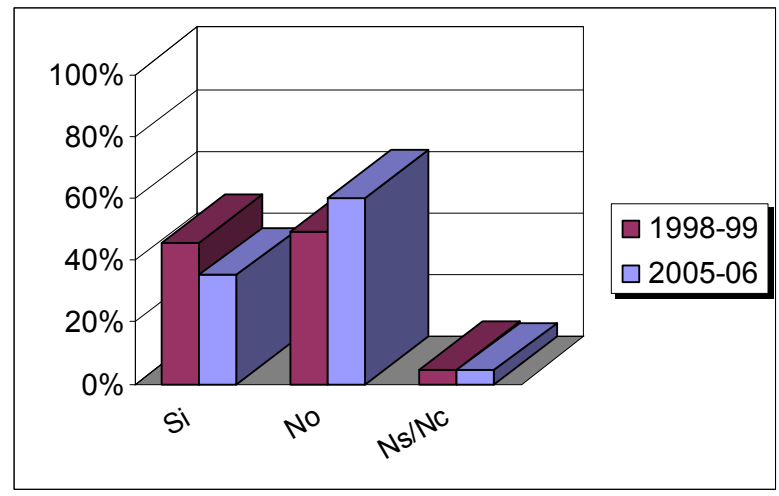

Gràfic 9. Existència de projecte de psicomotricitat

Del gràfic número 9 es desprèn que, el percentatge de centres que disposa d'un projecte d'intervenció psicomotriu ha baixat uns 10 punts percentuals el curs 2005-06 respecte del curs 1998-99. El curs 2005-06 tan sols el 35\% dels centres comptava amb un projecte en aquest àmbit.

Valoració: han sorprès els resultats obtinguts, pensàvem que la formació en psicomotricitat podria afavorir la realització i la consolidació de projectes de psicomotricitat. A la província, l'oferta formativa en psicomotricitat durant aquest període, set anys, ha estat considerable. A grans trets, es poden destacar: deu cursos de postgrau, uns dotze cursos de formació permanent del Departament d'Ensenyament primer, d'Educació després, alguns assessoraments a centre i alguna altra activitat relacionada amb la temàtica. Per això, es preveia un augment en el nombre d'escoles que haurien elaborat un projecte de psicomotricitat. Com s'ha vist, hi ha hagut una davallada del $10 \%$, que pensem que pot ser causada per dos motius. D'una banda, que els professionals que han fet una formació específica en 
psicomotricitat no realitzin aquesta pràctica a l'escola per diversos motius. De l'altra que, en haver-hi més professionals formats, el nivell d'exigència a I'hora de discernir entre un projecte de psicomotricitat o una programació de curs sigui més elevat. De fet, el curs 2005-06, en alguna de les respostes es fa aquest aclariment.

Es destaquen algunes observacions fetes pels participants, que consideren que "no tenir un projecte dificulta el treball de la psicomotricitat al cicle"; "els mestres estan d'acord a realitzar un projecte, ja que se'n veu la necessitat"; "per al curs següent es vol elaborar un projecte que abasti tot el cicle".

En el cas que el centre tingui projecte de psicomotricitat, es volia saber des de quin any, com es pot apreciar en el gràfic 10 :

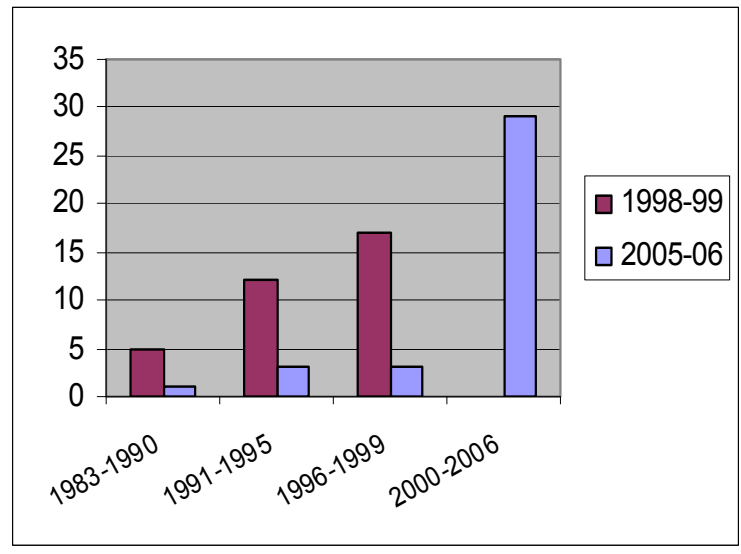

Gràfic 10. Any de realització del projecte

En observar les dades d'aquest ítem, cal aclarir que l'univers dels casos queda molt reduït, tan sols es tenen en compte les respostes en les quals existeix un projecte de psicomotricitat. S'ha vist en la pregunta anterior l'alt percentatge de centres que no en té. Si ens fixem en l'univers per realitzar el percentatge d'aquesta pregunta, es pot veure que ha quedat reduït a 34 respostes el curs 1998-99 i a 36 respostes el curs 2005-06.

Un cop dit això, es pot comprovar que entre els anys 2000 i 2006 és quan més projectes de psicomotricitat s'han elaborat, en total 29. Com és natural, en aquesta franja temporal (2005-2006) no es pot fer la comparació perquè no disposem de resultats de la primera aplicació, del curs 1998-99.

Valoració: tot i que es parteix d'un percentatge de respostes baix, és significatiu el nombre de projectes realitzats durant els set cursos del període estudiat. S'ha comentat en l'ítem anterior que l'oferta de formació específica durant aquest període ha estat molt àmplia En aquest cas, el que 
sorprèn és la davallada de projectes realitzats en els anys anteriors a aquest període. Cal qüestionar les possibles causes: influeix la mobilitat del professorat? Els projectes feien referència a una programació de psicomotricitat o d'educació física per a petits? El projecte s'inseria dins els principis educatius $\mathrm{i}$ els trets d'identitat del centre, o tan sols implicava el professional que I'havia realitzat?

Seguint amb el projecte de psicomotricitat, es volia esbrinar qui era el responsable de definir-lo.

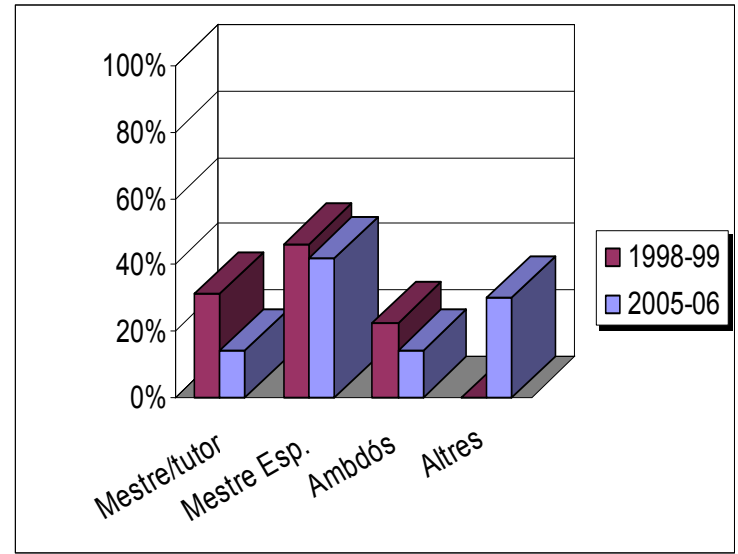

Gràfic 11. Responsable de definir el projecte

Cal aclarir que s'està treballant amb una mostra reduïda, ja que les respostes estaven restringides als centres que disposaven de projecte de psicomotricitat.

Es pot destacar que, en els dos casos, la persona responsable de definir el projecte que obté un percentatge més elevat és el mestre especialista. El curs 1998-99 amb el $46,3 \%$, i el $2005-06$ amb el $41,8 \%$ del total de respostes afirmatives.

Cal assenyalar la davallada del mestre/tutor en el disseny del projecte, que passa del $31,4 \%$ en la primera aplicació del qüestionari al $13,9 \%$ en la segona. Cal destacar la variable "altres", que ha augmentat en la segona onada de l'estudi i ha fet que les respostes quedin distribuïdes de la següent manera:

- En set de les respostes el projecte I'ha elaborat l'equip de mestres d'Educació Infantil.

- $\quad$ Cinc responen que són mestres especialistes d'Educació Física.

- $\quad$ Un parell matisen que és una programació i no un projecte.

- $\quad$ - Una resposta diu que s'està elaborant. 
Valoració: és interessant observar la tendència creixent que sigui l'equip de mestres d'Educació Infantil el que s'impliqui en la realització del projecte. Es garanteix el que es deia en els ítems anteriors, la importància que el projecte $s^{\prime}$ insereixi dins els principis educatius $i$ els trets d'identitat del centre i no depengui tan sols de la voluntat del professional que realitza la psicomotricitat, i més tenint en compte la mobilitat de mestres que hi ha actualment. Cal destacar també que en molts casos són els mestres especialistes en Educació Física els que assumeixen la intervenció psicomotriu en l'etapa d'Educació Infantil, tot i que, per llei, no està contemplat ni tenen una preparació específica.

Un altre dels aspectes que es va tenir en compte fou qui realitza la sessió de psicomotricitat.

Els resultats mostren que, tant el curs 1998-99 com el 2005-06, els docents que majoritàriament intervenen en la sessió de psicomotricitat són el mestre-tutor i el mestre especialista, ${ }^{3}$ amb resultats molt igualats. Tot i així, s'observa el creixement que experimenten el curs 2005-06 "altres perfils" diferents dels descrits, que, amb el $41 \%$, són els que majoritàriament porten a terme la intervenció en psicomotricitat.

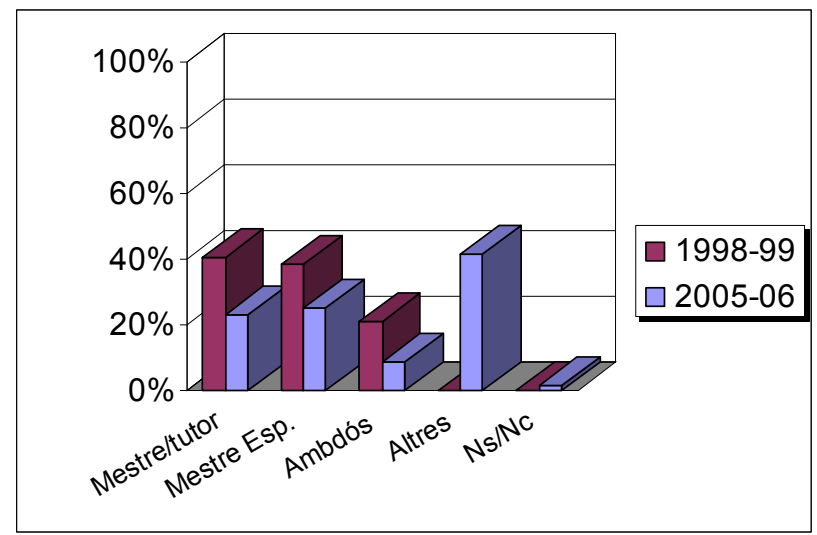

Gràfic 12. Docent que realitza la intervenció

El perfil dels professionals de les 55 respostes obtingudes és variat i en algun cas s'han donat respostes múltiples:

- 25 mestres especialistes d'Educació Física

- 15 mestres de suport

- 9 mestres tutores

- 2 mestres d'Educació Especial

- 2 fisioterapeutes

- 1 mestre de Llengua Estrangera

- 1 mestre d'Educació Musical 
Valoració: si es fa l'anàlisi de les respostes donades a "altres", no queda prou clar si les respostes s'ajusten al que es preguntava. Queden dubtes que no hagi estat ben entesa la pregunta, tot i els aclariments establerts. Per tant, creiem que els resultats d'aquest ítem són poc fiables. Caldrà fer-ne la valoració conjunta amb les dades obtingudes en la segona dimensió del qüestionari: perfil i formació de la persona responsable de la pràctica psicomotriu.

En relació al nombre de mestres que realitzen sessions de psicomotricitat al centre, a part del docent que respon el qüestionari, es poden veure els resultats al gràfic número 13

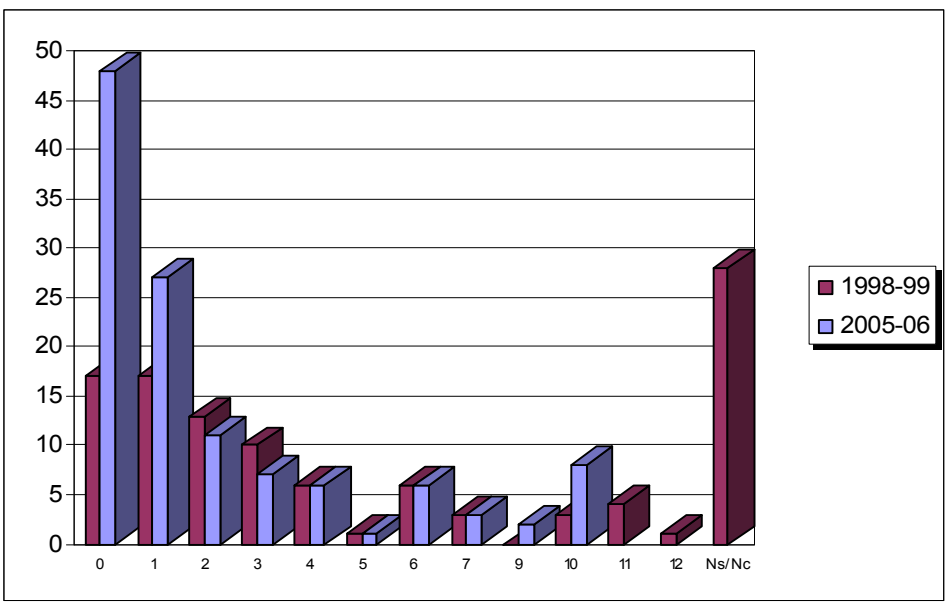

Gràfic 13. Nombre de docents que realitzen psicomotricitat al centre

Les dades recollides mostren que el nombre de mestres responsables de les sessions de psicomotricitat oscilla entre 1 i 12 en la primera aplicació i entre 1 i 9 en el segona. S'observa que, a mesura que augmenta el nombre de mestres que realitzen aquesta tasca, el percentatge de casos baixa. Cal destacar que els percentatges més alts $^{4}$ es troben en la participació d'1 o 2 mestres, amb el $27,53 \%$ en el primer cas i el $32,76 \%$ en el segon. Cal subratllar l'alt percentatge de docents que el curs 1998-99 no respon (25,69\%).

Valoració: com s'ha observat, en un percentatge força elevat no és un sol mestre el que realitza la sessió de psicomotricitat. Quan cada tutor fa la sessió al seu grup, o l'estructura organitzativa és una altra però requereix la intervenció de diferents mestres, aquests, per tal que la pràctica psicomotriu sigui coherent i estigui seqüenciada, han d'establir uns criteris comuns per a tot el cicle. 
Enllaçant amb les reflexions anteriors, ens interessava obtenir informació de la coordinació entre els mestres-tutors que porten a terme la sessió de psicomotricitat i el grau d'acord que existeix en els diferents nivells del cicle. Les respostes donades s'observen en el gràfic 14:

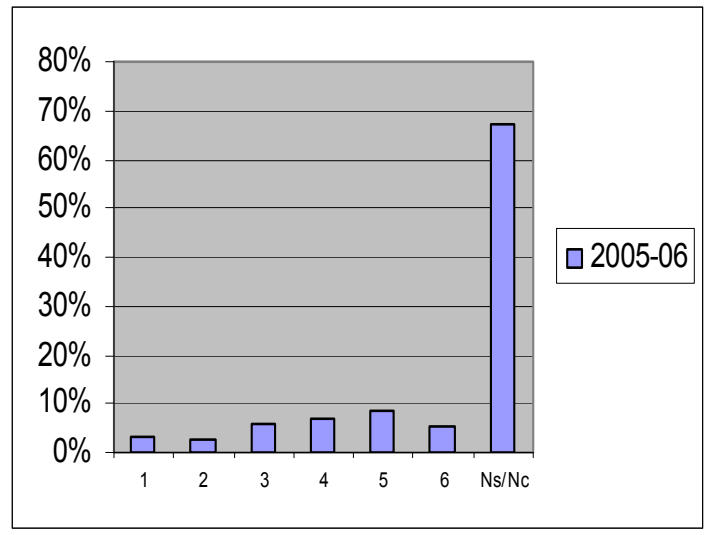

Gràfic 14. Coordinació entre els docents que realitzen psicomotricitat

La pregunta, molt relacionada amb l'anterior, es va formular en el segon qüestionari, el curs 2005-06, en observar el nombre de mestres que realitzaven les sessions de psicomotricitat en un mateix centre el curs 1998-99.

S'observen uns percentatges baixos en les valoracions de l'escala, destaca el 8,6\% com el més alt. En concret, tan sols el $20 \%$ dels casos puntuen amb un 4 o més sobre 6. Aquest percentatge augmenta molt, fins al $67,2 \%$, en les respostes $\mathrm{Ns} / \mathrm{Nc}$, fet que sorprèn, ja que sembla obvi que han de saber el nivell d'acord que hi ha amb les companyes i els companys de cicle amb relació a la intervenció psicomotriu.

D'altra banda, aquest percentatge augmenta considerablement si no es tenen en compte les respostes Ns/Nc. En aquest cas, són el 63,1\% els mestres que han puntuat amb 4 o més sobre 6.

Valoració: en aquest sentit s'esperaven unes respostes diferents. Atenent els resultats que valoren aquest ítem, es considera que la coordinació i l'establiment de criteris i acords comuns entre els diferents mestres-tutors amb relació a la intervenció psicomotriu és més baix del que s'esperava. Possiblement, si el centre disposés d'un projecte de psicomotricitat, els resultats serien més satisfactoris.

Finalment, es demanava al professorat que seleccionés tres paraules significatives relacionades amb el concepte de psicomotricitat.

Aquesta pregunta qualitativa ha permès tenir informació de quines són les paraules que, segons els enquestats, conformen el nucli d'aquest concepte. 
Per fer una estimació de la informació, a causa de l'elevat nombre de paraules obtingudes, 312 de 327 possibles el curs 1998-99 i 339 de 348 possibles el curs 200506 , ha estat necessari, en alguns casos, agrupar-les per similituds semàntiques.

S'han establert categories, tot i saber que "la categorització constitueix un acte de simplificació, i simplificar significa arriscar-se $[\ldots]^{\prime \prime}{ }^{5}$ S'han tingut en compte els criteris següents:

- Una categoria engloba les paraules que fan referència al cos. S'entén el cos com una globalitat que integra el moviment, l'emoció i el pensament. "L'esquema corporal és l'organització de les sensacions relatives al propi cos en relació amb les dades aconseguides a partir del mon exterior". ${ }^{6}$

- Les paraules que impliquen moviment s'han agrupat en una categoria, concretament "moviment i motricitat". Els diccionaris consultats defineixen el moviment com "I'acció per la qual un cos o alguna de les seves parts canvia de lloc o posició". Pel que fa a la motricitat, com la "capacitat de l'ésser viu de produir moviment per si mateix, pot ser d'una part del cos o de la totalitat". ${ }^{7}$ D'acord amb Sugrañes i altres (2007), "considerem que el moviment ha de ser voluntari, en el sentit que hi ha d'haver una motivació de base que impulsi l'infant a moure's".

- Un altre grup engloba les conductes motrius bàsiques: equilibri, coordinació dinàmica general i coordinació oculomanual (L. Picq i P. Vayer, 1969).

- Igualment, atenent la classificació dels mateixos autors, s'agrupen en les conductes neuromotrius: el to, la postura i la lateralitat (L. Picq i P. Vayer, 1969).

- Seguint els autors que s'acaben de citar, un altre grup el formen les conductes perceptivomotrius, que en aquest cas tan sols agruparan els termes relacionats amb la percepció de l'entorn, l'organització de l'espai i del temps, ja que els termes relacionats amb la percepció d'un mateix s'han inclòs en la categoria de cos.

- S'estableix una categoria que agrupa les paraules relacionades amb les capacitats mentals/cognitives: intel-ligència, percepció, representació, simbologia, raonament, interiorització, atenció.

Els termes que s'anomenen un sol cop, com és el cas d'infantil, dèficit, persona, organització, força, grafomotricitat, domini, escolar, agilitat i educació, no s'han tingut en compte a l'hora d'establir les categories, perquè s'ha considerat que tenen un valor molt baix en l'anàlisi global dels resultats.

Comparant les categories establertes a partir de les respostes dels dos qüestionaris, l'inicial i el final, tan sols n'hi ha una que no coincideix $\left(^{* \star}\right)$, el curs 1998-99 fa referència al material, i el curs 2005-06 als aspectes afectivoemocionals. 
El gràfic número15 mostra els resultats dels termes que els docents consideren més significatius amb relació al concepte de psicomotricitat:

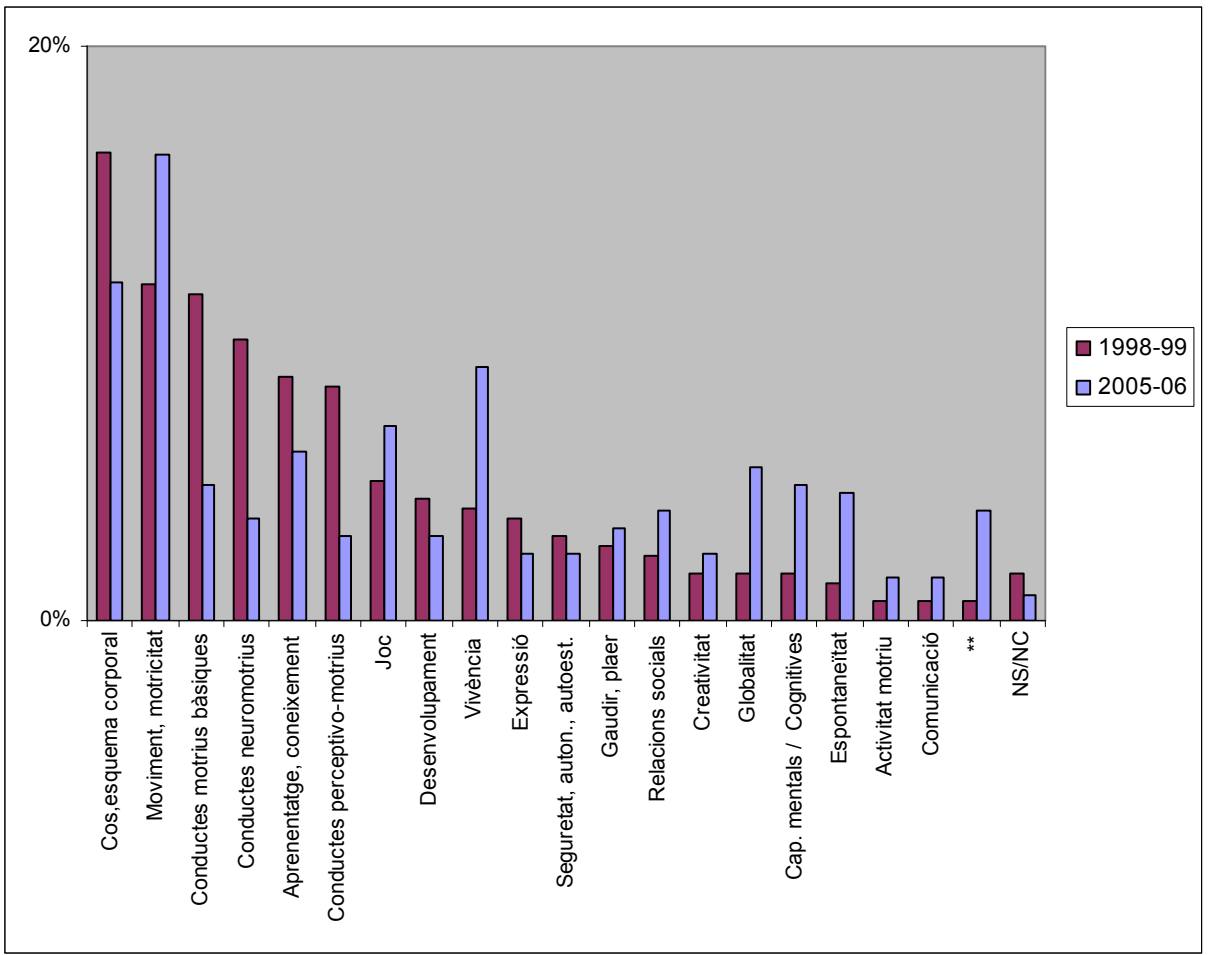

Gràfic 15. Termes significatius amb relació al concepte de psicomotricitat

El tractament estadístic d'aquesta pregunta ha buscat la possibilitat de comparar els diferents conceptes que els entrevistats anaven enumerant. D'aquesta forma, s'han agrupat totes les respostes en les categories descrites segons el seu sentit i s'han llistat per les dues onades en què es va realitzar l'estudi.

Com s'observa en el gràfic, els termes més triats pel professorat fan referència a conceptes essencials de la psicomotricitat. Pel que fa al curs 1998-99, les paraules més anomenades han estat, en aquest ordre: cos, moviment i conductes motrius bàsiques, i el curs 2005-06, moviment, cos i vivència. En ambdós casos els percentatges de les dues primeres paraules s'han invertit.

Valoració: tant en el curs 1998-99 com en el 2005-06, les paraules més citades pels mestres han estat cos i moviment. Com ja s'ha dit en la introducció, el cos i el moviment són eixos bàsics tant en la psicomotricitat com en I'Educació Infantil. Com afirma J.L. Pastor (2001: 5), "[...] posiblemente, también se requiera decidir cuál de estos conceptos, cuerpo o movimiento, ha de constituir el punto de partida y, por tanto, cuál de ellos 
condiciona la comprensión del otro o cuál de los dos incide más decisivamente en la construcción y significación del otro".

També cal destacar la paraula globalitat, que el curs 2005-06 ha augmentat considerablement i és bàsica en la comprensió de l'infant, de la mateixa manera que ho han fet els aspectes afectivoemocionals i els mentals, que formen part d'aquesta globalitat.

\section{Conclusions}

Amb la informació obtinguda amb els qüestionaris realitzats pels docents, s'ha pogut conèixer quina evolució ha experimentat la realitat de la psicomotricitat en el període de set cursos acadèmics als centres d'Educació Infantil de les comarques de Tarragona. Com s'ha assenyalat, en general s'ha vist una millora en la situació existent, tot i que es constaten carències en alguns aspectes.

Els centres que han participat en l'estudi es troben repartits geogràficament per les deu comarques tarragonines, la seva distribució ha estat més equitativa en la segona aplicació del qüestionari.

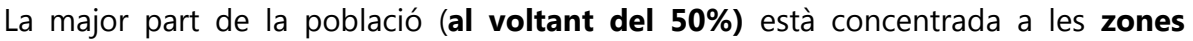
urbanes, tot i que les poblacions semiurbanes i rurals estan representades de manera equitativa, aproximadament un $25 \%$ dels centres es troben en aquest tipus de poblacions, especialment el curs 2005-06.

La mostra està formada per un ampli predomini de centres públics, percentatge que augmenta en la segona aplicació de l'instrument. Els centres concertats i els privats tenen una representació molt més baixa, especialment els privats en la segona onada de l'estudi. Aquest fet pot ser degut a la creació de nous CEIP i llars d'infants municipals, que s'han vist incrementats els darrers anys.

La valoració que els centres atorguen a la psicomotricitat és positiva, les puntuacions més destacades se situen en la franja alta de l'escala en el $\mathbf{7 5 \%}$ dels casos i globalment coincideixen en els dos moments de l'estudi. Sembla que les institucions educatives estan d'acord en la importància de la psicomotricitat per al desenvolupament integral de l'infant.

Cal dir, però, que a la pràctica, i a partir d'observacions fetes pels entrevistats, es creu que s'ha millorat poc i que la importància que s'atorga a la psicomotricitat en molts casos també depèn de la informació o la sensibilització en aquesta àrea de l'equip directiu del centre.

La pràctica psicomotriu té més incidència en el període de 3 a 6 anys i és especialment elevada el curs 2005-06. Un motiu pot ser la baixa participació de llars d'infants en la mostra que ha format part de l'estudi. La intervenció en gairebé la totalitat dels centres es realitza en l'àmbit educatiu. 
Les dades que aporten els professionals dels centres estudiats sobre la valoració de la psicomotricitat no sempre es corresponen amb l'existència d'un projecte que organitzi, planifiqui i situï la línia d'escola amb relació a la psicomotricitat educativa. Durant la primera fase de recollida de dades, efectuada el curs 1998-99, gairebé la meitat de les escoles manifestava que no tenia aquest document. En les dades recollides el curs 2005-06 s'observa un augment d'escoles (10\%) que manifesten que no tenen projecte de psicomotricitat. No obstant això, la pregunta dirigida a les escoles amb projecte que tracta de situar l'antiguitat d'aquest aporta dades incoherents que només poden explicar-se a partir de dos fets: l'existència de plantilles poc estables i la reformulació del concepte de projecte que han pogut fer els professionals participants en l'estudi. A la llum d'aquestes dades, es té el convenciment que la psicomotricitat ha de formar part del Projecte Educatiu de Centre per garantir una línia de treball que no depengui de la mobilitat del professorat i, en molts casos, de la seva assignació a l'últim docent que arriba.

En els casos de centres que han elaborat un projecte psicomotor, els responsables de definir-lo solen ser els mestres especialistes, també, i en segon terme, són els mateixos tutors els que han dissenyat el projecte, i en menor grau ha estat una tasca conjunta de tutors i especialistes, si es fa referència a la primera aplicació del qüestionari. Les dades de la segona aplicació varien força, ja que en segon terme aquest treball el realitzen els mestres que formen el grup "altres professionals".

Els termes més destacats pels docents per definir el concepte de psicomotricitat han estat "cos" i "moviment" en els dos moments de la recopilació de dades. Cos i moviment entesos més enllà del terme que els descriu, en l'amplitud del concepte, són complementaris i imprescindibles en psicomotricitat, es pot dir que en conformen el nucli. Si es revisen les múltiples definicions de psicomotricitat es pot constatar que aquests dos conceptes formen part de totes.

\section{Notas}

${ }^{1}$ Del llistat de centres proporcionat pel Departament d'Ensenyament, Delegació de Tarragona, s'han desestimat els centres que apareixen a les dues llistes: CEIPS i EEI. Es tracta de collegis que també disposen del cicle de llar d'infants.

2 Segons la classificació establerta per I'Institut Nacional d'Estadística de Catalunya (IDESCAT), es consideren tres tipus de poblacions: rural, de 2.000 habitants o menys; semirural o intermèdia, de 2.001 a 10.000 habitants, i urbana, de més de 10.000 habitants.

${ }^{3}$ El "mestre especialista" fa referència a si són especialistes en psicomotricitat, és a dir, si tenen una formació específica en aquest àmbit.

${ }^{4}$ Es considera el valor "0" vàlid, tenint en compte com està formulada la pregunta, valor que indica que la sessió es realitza exclusivament per l'entrevistat. 
${ }^{5}$ J. M. Gore citat per M.C. Silveira (2002: 19).

${ }^{6}$ E. Sugrañes, M.A. Àngel i altres (2007: 81).

${ }^{7}$ Diccionari General de la Llengua Catalana. Pompeu Fabra.

\section{Referències bibliogràfiques}

Ajuriaguerra, J. (1979). Manual de psiquiatría infantil. Barcelona, Toray-Masson.

Anton, M. (1979). La psicomotricitat al parvulari. Barcelona, Laia.

- (1986). Taller de Psicomotricitat. Col-lecció de vídeos didàctics. Barcelona, Televisió de Catalunya.

Berruezo, P.P. (1995). El cuerpo, el desarrollo y la psicomotricidad. Psicomotricidad. Revista de Estudios y Experiencias, 49, 1, pp. 15-26.

Boulch, J. Le (1972). La educación por el movimiento en edad escolar. Buenos Aires, Paidós.

- (1982). Hacia una ciencia del movimiento humano. Buenos Aires, Paidós.

(1983). El desarrollo psicomotor desde el nacimiento a los 6 años. Madrid, Doñate.

Cratty, B.J. (1982). Desarrollo perceptual y motor en los niños. Barcelona: Paidós.

Delval, J. (2003). Movimiento, emoción y pensamiento. A: DIVERSOS AUTORS. Movimiento, emoción y pensamiento. Madrid: Centro Superior de Estudios Universitarios La Salle i FAPEE, p. 33-42.

Duverger, M. (1996). Métodos de las ciencias sociales. Barcelona, Ariel Sociológica.

Ferreres, V. i González Soto A.P. [ed.]: Evaluación para la mejora de los centros docentes. Madrid, Praxis, 2006.

Franc, N. (2001). La intervención psicomotriz en educación. Revista Iberoamericana de Psicomotricidad y Técnicas Corporales nº1, pp. 5-18.

Gessell, A. I Amatruda, C. (1972). Embrionología de la conducta. Buenos Aires: Paidós. [Original 1945]

Lapierre, A. i Aucouturier, B. (1977a) Educación vivenciada. Asociación de contrastes, estructuras y ritmos. Barcelona: Científico-Médica.

- (1977b). Educación vivenciada Los contrastes y el descubrimiento de las nociones fundamentales. Barcelona: Científico-Médica.

— (1977c) Los matices. Barcelona: Científico-Médica. 
Montessori, M. (1937). El método de la pedagogía científica. Barcelona, Arluce.

Pastor Pradillo, J.L.: Psicomotricidad escolar. Guadalajara, Servicio Publicaciones Universidad de Alcalá, 1994.

- (2001). "La significación educativa del movimiento". Revista Ibericoamericana de Psicomotricdad y Técnicas corporales, 3, p. 5-20.

(2002). Fundamentación conceptual para una intervención psicomotriz en Educación Física. Barcelona, Inde.

Perinat, A. (2003). Psicología del desarrollo. Un enfoque sistémico. Barcelona: UOC.

Piaget, J. (1961). La formación del símbolo en el niño. México, Fondo de Cultura Económica.

- (1975). El nacimiento de la inteligencia en el niño. Madrid, Aguilar.

Picq, L. i Vayer, P. (1977). Educación Psicomotriz y retraso mental. Barcelona, Científico-Médica. [Original 1969]

Rosseuau, J.J. http://www.pensament.com/filoxarxa/filoxarxa/FiloXarxa.htm

Sierra Bravo, R. (1984). Técnicas de investigación social. Madrid: Paraninfo.

Silveira, M.C. (2002). Rutines, activitat a l'escola. Infancia, n² 43, pp. 19-26.

Sugrañes, E. y Àngel, M.A. (2007). La educación psicomotriz (3-8 años). Barcelona, Graó.

Tejada, J. (1997). El proceso de investigación científica. Barcelona, Fundación "La Caixa".

Vaca, M. (1986). El cuerpo entra en la escuela. Salamanca, ICE.

- (1996). La Educación Física en la Educación Formal. Palencia, Asociación Cultural Cuerpo, Educación y Motricidad.

Vygotsky, L.S. (1979). El desarrollo de los procesos psicológicos superiores. Barcelona, Crítica.

Wallon, H.: (1969). Los orígenes del carácter en el niño. Buenos Aires, Lautaro. [Original 1934]

— (1978). Del acto al pensamiento. Buenos Aires, Psiqué. [Original 1942]

(1976). La evolución psicológica del niño. Buenos Aires, Psiqué. [Original 1947]

\section{Nota biogràfica}

Isabel Viscarro Tomàs. Llicenciada en Educació Física i Psicomotricista. Doctora per la Universitat Rovira i Virgili (Educació). Professora Titular d'Escola Universitària de 
l'àrea de Didàctica de la Expressió Corporal. Departament de Pedagogia de la Universitat Rovira i Virgili. Directora i coordinadora de cursos de postgrau i d'extensió universitària en Educació Psicomotriu. Línees de recerca: Educació psicomotriu; Investigació i innovació docent en educació superior. Telèfon: 977558091; adreça electrònica: isabel.viscarro@urv.cat

Saturnino Gimeno Martín. Mestre. Diplomat Educació Física (INEF Madrid). Llicenciat Historia (UB). Llicenciat Educació Física (Politècnica Madrid). Doctor Ciències de I'Educació (URV).Titular Universitat (Area Didàctica de I'Expressió Corporal, Departament de Pedagogia. Coordinador Doctorat Interunivrsitari "Educació Física i Esport: didàctica i desenvolupament professional". Línees de recerca: Didàctica de l'educació física; Activitats físiques en el Medi Natural ; Educació física, esports i valors. Telèfon: 977558091; adreça electrònica: saturnino.gimeno@urv.cat

Montserrat Anton Rosera. Mestra. Llicenciada en Filosofia i Lletres. Ciències de I'Educació. Doctora per la Universitat Autònoma de Barcelona. Professora Titular Universitat del Departament de Didàctica de l'Expressió Musical, Plàstica i Corporal de la Universitat Autònoma de Barcelona. Directora del Institut de Ciències de l'Educació de la UAB. Línees de recerca: La pràctica psicomotriu de 0 a 8 anys; la observació en l'educació infantil; xarxes d'atenció a la petita infància. Telèfon : 935811077 ; adreça electrònica: montserrat.anton@uab.cat 